\title{
Optimization of parameters of the spraying device at etching of potato tubers
}

\author{
Svetlana M. Borisova ${ }^{1}$, Sergey K. Papusha ${ }^{1,{ }^{*}}$, and Nikolay A. Nikitenko ${ }^{1}$ \\ ${ }^{1}$ FSBEI HE Kuban State Agrarian University named after I.T.Trubilin, Krasnodar, Russian Federation
}

\begin{abstract}
The article considers the treatment of potatoes with protective and stimulating substances before planting, using a slit-type disperser, a finely dispersed low-volume spray on the surface of the processing object. The article has a research character, which is expressed in the fact that the analysis of methods and means for processing potatoes with protective and stimulating substances, as well as excerpts from the works of leading scientists on the subject under study are promising scientific developments in the form of patent analysis, which provide optimal flow of the technological process, there were shown their shortcomings and solutions to these problems. There was formulated the main problem of general etching constructions. Also, there was specified the technology of potato tubers treatment with protective-stimulating preparation, the description and the course of technological process are cited. As a result of the work done, a constructive scheme of the device for the treatment of tubers with protective and stimulating liquids by means of slit sprayers is proposed. The article also provides the optimization of parameters of a pneumatic slit sprayer for treatment of tubers with protective and stimulating liquids. The conclusions set out the main results achieved so far.
\end{abstract}

Potatoes are one of the most important sources of human nutrition and animal feeding. According to energy data, it ranks fifth after winter wheat, corn, rice and barley.

The role of measures to protect potatoes from diseases and pests is increasing in modern conditions.

Analyzing the technical characteristics of some samples of potato tubers, we see that agriculture is moving to progressive consumption rates of preparations in $60-180 \mathrm{ml} / \mathrm{t}$ for potatoes instead of the traditional ones - 2-15 1/t.

Moreover, the etching device using a semi-dry method of processing [2] and such process indicators as the quality of dispersion and the uniformity of the working fluid deposition on the tubers surface are of great interest.

Taking into account the deficiencies in existing designs for the treatment of potato tubers, we have developed a prototype of the etching device with pneumatic slit dispersing devices of Kuban State Agrarian University [3] for ultra-low volume treatment of potato tubers by preparations of broad spectrum of operation.

\footnotetext{
${ }^{*}$ Corresponding author: sergey belousov87@mail.ru
} 
The device for the study of structural and operating parameters of transporting devices of potato tubers and devices for applying the protective and stimulating agents to tubers in sprayed form (in the form of highly dispersed jets) are represented by a hopper for tubers of rolled rod-shaped surface of the receiving hopper, a device for semi-dry etching of tubers and a compressor unit.

The bracket with a platform for mounting pneumatic slit sprayers, connected with a hydraulic line with a container for the working liquid fixed on the site with sprayers with the ability to regulate the support of the liquid in the sprayers by moving it vertically relative to the outlets of the feeding tubes of the sprayers is installed on the frame of the compressor.

The operation of the device is as follows. The tubers move to an inclined rod-shaped surface from the hopper. Its angle of inclination allows the tubers to roll down the rods without slipping to be able to process the tubers with working liquid evenly. The distance between the rods is adjusted depending on the size of the tubers, which were sorted on the sorted devices before etching.

The work of the etching part of the device is as follows. The sprayer fixed on the site is supplied with compressed air under pressure, adjustable in accordance with the processing conditions, and injects the working liquid, which comes to the sprayers from the tank by gravity. The working liquid is mixed with air and the air-droplet jet is formed directed at the rolling tubers. The working process of etching is stopped (Fig 1), by ceasing the supply of working liquid by a crane or air supply to the pneumatic line to the sprayers. Taken into account the need to design the spray devices and direction control units of tubers, which can be successfully applied to devices for etching, we investigated the odds of rolling the tubers over a variety of surfaces (rubber, metal, and wood). At the same time, tubers differing in surface properties (dry and moist) and surface shape (round and oval) were used for the experiment.

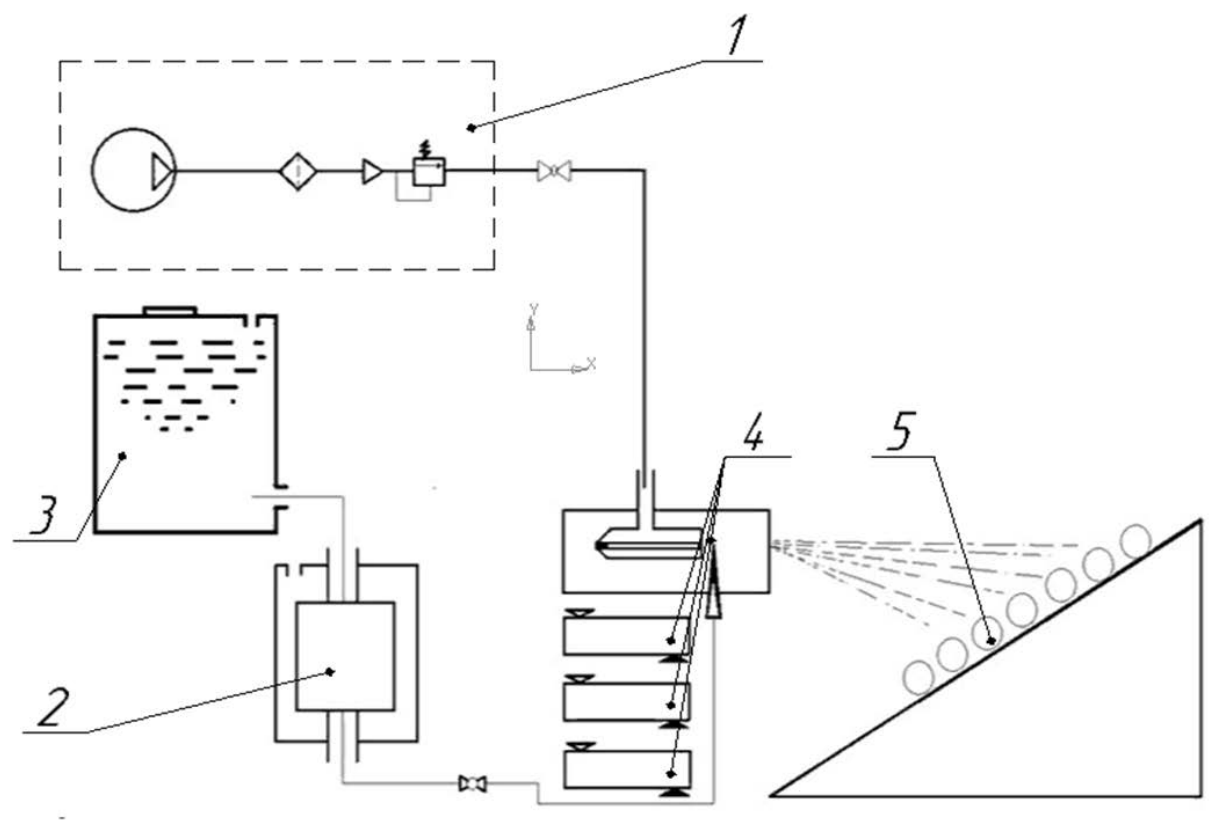

1 - compressor devices; 2 - leveling tank; 3 - tank with working liquid; 4 - sprayers; 5 - direction control unit of tubers.

Fig. 1. Scheme of accessory for treatment of tubers with protective-stimulating liquids. 
Optimization of the parameters of the pneumatic slit sprayer for the treatment of tubers with protective and stimulating liquids was carried out using a three-factor experiment [1, 4].

One of the most important parameters characterizing the operation of liquid dispensers is its performance. It is this parameter that will determine the method of full-volume, lowvolume or ultra-low-volume spraying.

We reviewed and analyzed the slit pneumatic liquid dispenser of an open type. This dispenser has the slit nozzle size $(5 \times 0.3) \mathrm{mm}^{2}$, the jet is pear-shaped, the inlet diameter of the pneumatic line was $6 \mathrm{~mm}$. There was studied the influence of three factors and there were fixed their values at optimal levels. The full factorial experiment (PFE) of the symmetric composite plan of the VC type was used for the researches. Factors, intervals and levels of variation are presented in Table 1.

Table 1. Factors, intervals and levels of variation.

\begin{tabular}{|l|c|c|c|c|c|}
\hline \multirow{2}{*}{ Factors } & \multirow{2}{*}{$\begin{array}{c}\text { Encoded } \\
\text { symbol }\end{array}$} & Interval of & \multicolumn{3}{|c|}{ Levels of factors } \\
\cline { 4 - 6 } & & & -1 & 0 & +1 \\
\hline Diameter of feeding tube (d),MM & $\mathrm{x}_{1}$ & 2 & 2 & 4 & 6 \\
\hline Air pressure (P), MPa & $\mathrm{x}_{2}$ & 0,05 & 0,1 & 0,15 & 0,2 \\
\hline Position of leveling tank & $\mathrm{x}_{3}$ & 0,1 & 2 & 3 & 4 \\
\hline
\end{tabular}

The levels of the factors were chosen in such a way that their optimal values were calculated theoretically or they took into account purely practical values of the parameters and fell into the centre of the variation interval.

The maximum value for the first factor $\mathrm{x}^{1}$ was the diameter of the feeding tube of the sprayer $\mathrm{d}_{\min }=2 \mathrm{~mm}$, which corresponds to the variation interval.

Existing sprayers operate with a diameter of not more than $3 \mathrm{~mm}$, which leads to their clogging and the need for clearing during operation, the same ones who use large holes are mainly limited in the range of preparations, as they form large drops that do not meet the agrotechnical requirements for the process of treatment.

For the second factor $\mathrm{x}^{2}$ there $\mathrm{w}$ was adopted the parameters of air pressure in the pneumatic pipeline which may be used with the tractor, which maximum pressure from the compressor is not more than $6 \mathrm{MPa}$, and the decrease in operating pressure allows to provide air with a sufficient number of sprayers installed on soil cultivating or sowing units.

The position of the leveling tank in height was taken from the considerations of the efficiency of the sprayers and the design parameter of the interposition, taken when applied to the soil simultaneously with other technological operations.

Other design parameters of the sprayer are considered inappropriate, since they are not decisive according to preliminary studies.

After mathematical processing of experimental data, the regression equation for the performance of sprayers is obtained

$$
\begin{gathered}
\mathrm{y}=219,9375+43,4 \mathrm{x}_{1}+49,9 \mathrm{x}_{2}-109,1 \mathrm{x}_{3}+11,125 \mathrm{x}_{1} \mathrm{x}_{2}-26,875 \mathrm{x}_{1} \mathrm{x}_{3}-58,875 \mathrm{x}_{2} \mathrm{x}_{3}+ \\
34,0103 \mathrm{x}_{1}^{2}-27,4897 \mathrm{x}_{2}{ }^{2}+85,5103 \mathrm{x}_{3}{ }^{2}
\end{gathered}
$$

where $\mathrm{Y}$ - performance of the sprayer, $\mathrm{ml} / \mathrm{min}$

Substituting in the original equation the values of $\mathrm{X}_{1}, \mathrm{x}_{2}, \mathrm{X}_{3}$, there was found the value of the optimization parameter in the center of the response surface

$$
\mathrm{Y}_{1}=180,6 \mathrm{ml} / \mathrm{min}
$$

After determining the angle of rotation of the coordinate axes to align with the main 
axes of the figure, we write the regression equation in the canonical.

The surface of the response has a parabolic type and the center minimax

For a more detailed representation of the response surface, we study it using twodimensional sections. From Figure 3 it can be seen that the change in the value $\left(\mathrm{x}_{2}\right)$ within the experiment affects the performance of the parabola law, that is, with an increase in pressure to $0.15 \mathrm{MPa}$ liquid flow increases and then decreases, and the flow increases with an increase in the diameter, starting from the center of the plan with increasing the diameter.

According to the regression equation, the most significant is the position of the leveling tank in height (that is, the head of the working liquid).

There were determined the rolling angles of tubers, which were 13-20 on the rod-shaped direction control unit, and the distance between the rods is adjusted from $50 \mathrm{~mm}$.

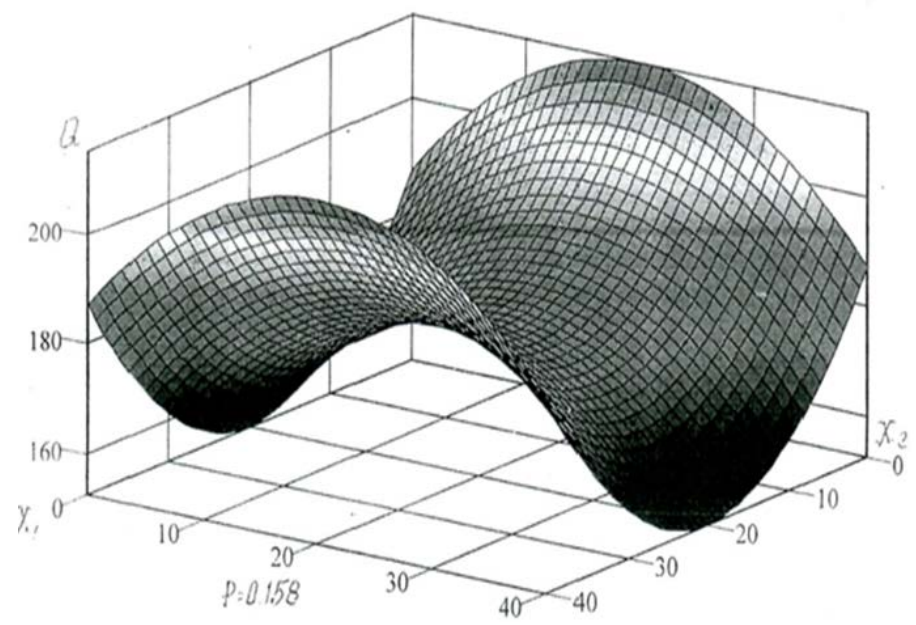

Fig. 2. Surface of dependence of the dispenser performance from a diameter of the feeding tube and pressure

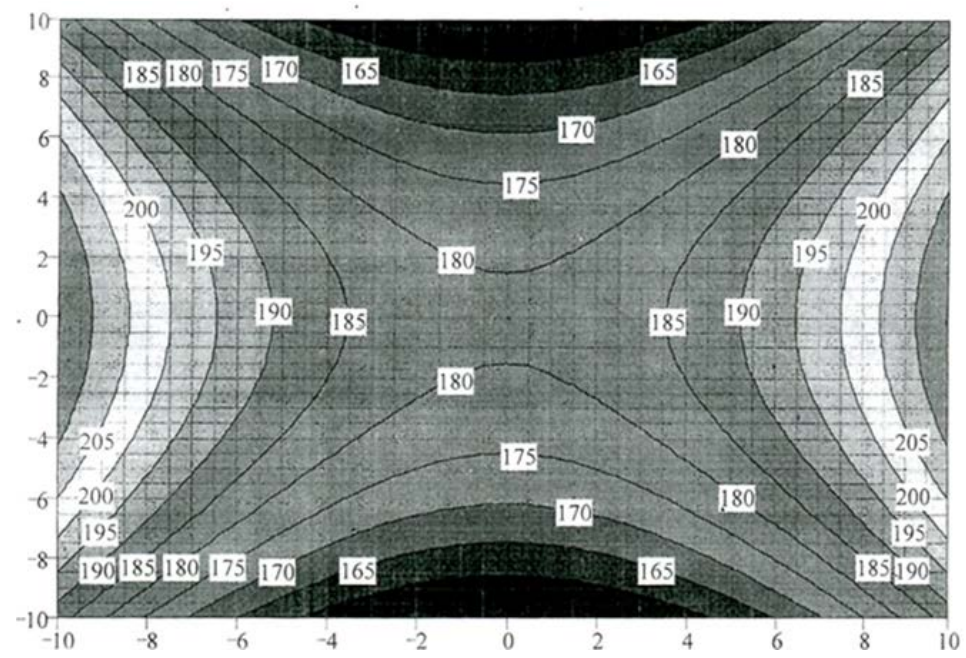

Fig. 3. 2-D section of response surface on performance 
Thus, the design of ultra low-volume etching device with finger direction control unit was determined and developed on the basis of scientific analysis of existing means of mechanization for tuber etching. The spraying device with pneumatic slit sprayers was selected for ultra-low volume treatment. The number of nozzles is $1-4$ pcs. The energy source is a compressor with power supply from the external network. The optimal mode of the sprayer operation is determined on the basis of a 3-factor experiment and is $180 \mathrm{ml} / \mathrm{min}$ in the center of the plan at air pressure of about $0.15 \mathrm{MPa}$ at static pressure. There were determined the rolling angles of tubers which were 13-20 on the rod-shaped direction control unit and the distance between the rods is adjusted from $50 \mathrm{~mm}$.

The use of the developed device will significantly reduce the consumption and improve the quality of processing of potato tubers with protective and stimulating liquids, which will inevitably lead to a decrease in production costs.

\section{References}

1. Borisova S.M. Seed treater / Borisova S.M., Maslov G.G., Tsybulevsky V.V., Trubilin E.I., Kozhan V.N. / patent for invention RUS 2316164 01.08.2006.

2. Koval Z.M., Characteristics of the slotted atomizer of liquid.// International Research Journal. - Yekaterinburg - 2016. № 8-3 (50). Pp. 174-177.

3. Veletsky I. N., Lysov A. K., Lepekhin N. S., et al. Plant Protection Mechanization: A Handbook. M.: IN Agropromizdat, 1992-223.

4. Vinevsky E.I. Optimization of parameters of mechanization tools by the method of planning a multifactor experiment / Vinevsky EI, Popov GV, Papusha SK, Shidlovsky EV, Ognyanik AV, Vinevskaya NN, Bukatkin R.N. / Collection of scientific works of the All-Russian Scientific Research Institute of Tobacco, Shag and Tobacco Products. 2010. No. 179. S. 300-312. 